$\mathrm{te}^{3,4}$. No estado de São Paulo, a prevalência de meningite por Hib variou de $13,16 \%$ (sobre todas as etiologias de meningite) em 1994, para 3,81\%, em $2001^{9}$.

A utilização de novas vacinas como as vacinas conjugadas para pneumococo e para meningococo $\mathrm{C}$ devem no futuro modificar ainda mais o perfil etiológico das meningites bacterianas. $O$ pediatra deve estar atento para a realidade local e possivelmente transitória do perfil etiológico das doenças infecciosas e da possibilidade de utilizar meios preventivos que têm ação muito mais duradoura e eficaz no controle das doenças.

\section{Referências bibliográficas}

1. Farhat CK, Ribeiro AF, Musa SCF, Succi RCM, Marques SR, Carvalho ES. Meningites na Infância - estudo de 777 casos - 1 . Etiologia. XXXI Congresso Brasileiro de Pediatria. Tema $\mathrm{n}^{\circ}$ 390. Rev Pediatr Ceará 2000; 1(supl.1):215.

2. Mantese OC, Hirano J, Santos IC, Silva VM, Castro E. Perfil etiológico das meningites bacterianas em crianças. J Pediatr (Rio J) 2002;78(6):467-74.
3. Romanelli RMC, Araújo CA, Dias MW, Boucinhas F, Carvalho IR, Martins NRL, et al. Etiologia e evolução das meningites bacterianas em centro de pediatria. J Pediatr (Rio J) 2002; 78: 24-30.

4. Takemi NS, Andrade SM Meningite por Haemophilus influenzae tipo b em cidades do Estado do Paraná. J Pediatr (Rio J) 2001;77:287-92.

5. FUNASA - Programa Nacional de Imunizações. Disponível em: http://www.funasa.gov.br/imu/imu01.htm

6. Forleo-Neto E, Oliveira CF, Maluf EMCP, Bataglin C, Araújo JMR, Kunz Jr. LF, et al. Decrease point prevalence of Haemophilus influenza type b (Hib) oropharyngeal colonization by mass immunization of Brazilian children less than 5 years old with Hib polyribosylribitol phosphate polyssacharide-tetanus toxoid conjugate vaccine in combination with diphteria-tetanus toxoids- pertussis vaccine. J Infect Dis 1999;180(4):1153-8.

7. CDC. Progress toward elimination of Haemophilus influenzae type $b$ disease among infants and children - United States, 19871997. MMWR 1998;47:993-8.

8. FUNASA. Casos confirmados, segundo o período de diagnóstico e local de residência, por UF. Brasil, 1980-2001. Em: http:// www.funasa.gov.br/epi/pdfs

9. SVE-DDT respiratória-CVE/SINAM (1989-2001). Meningites determinadas segundo os principais agentes etiológicos - Estado de São Paulo 1989 a 2001. Disponível em: http:// www.cve.Saude.sp.gov.br/htm/resp/meni_detetio8901.htm

\title{
Tubos de ventilação
}

\author{
Tympanostomy tubes
}

Manoel de Nóbrega*

$\mathbf{N}_{\mathrm{o}}$ ano ao pediatra por doenças do ouvido médio e/ou disfunção da tuba auditiva atinge a cifra de 1.394 .000 consultas/ano. Os gastos com medicamentos são significativamente mais caros no tratamento da otite média recorrente (US\$ 124,64), quando comparados a um tratamento inicial (US\$ 107,81). São gastos anualmente três e meio bilhões de dólares somente para o tratamento clínico das doenças da orelha média ${ }^{1}$.

Como conseqüência, mais de 1 milhão de crianças são submetidas anualmente à colocação de tubo de ventilação (TV), constituindo mais de 2 milhões de TV colocados por ano ${ }^{2}$.

\footnotetext{
* Mestre em Otorrinolaringologia pela UNIFESP-EPM.
}

De acordo com Saffer et al. ${ }^{3}$, a colocação de TV é benéfica para pacientes com hipoacusia bilateral, decorrente de otite média crônica secretora, considerando-se a história natural da doença, os riscos de resistência bacteriana, os benefícios comprovados e a técnica simples de colocação. Estes TVs serão indicados sempre que o curso da otite média crônica secretora, acompanhada ativamente por três a seis meses, evoluir desfavoravelmente naquelas crianças de baixo risco.

Saffer et al. ${ }^{3}$ destacam ainda que não se deve esquecer que um único procedimento cirúrgico não soluciona o problema do paciente em tratamento, uma vez que a resolução para a otite média crônica secretora está baseada no crescimento da criança com o desenvolvimento da tuba auditiva e da sua imunidade de forma adequada. 
A cirurgia para a colocação de TV continua muito freqüente e bastante atual. As indicações de miringotomia e colocação de TV são as seguintes ${ }^{4}$ :

- otite média crônica secretora assintomática, que não apresenta melhora com o tratamento clínico, e que persiste por mais de três meses, quando bilateral, e por mais de seis meses, se unilateral. A cirurgia está indicada mais precocemente, quando há perda auditiva maior do que 20 decibéis $(\mathrm{dB})$, retardo na fala ou linguagem, bolsa de retração, vertigem ou desequilíbrio, zumbidos. Está também indicada quando há episódios recorrentes de otite média secretora, em que a duração de cada episódio não caracteriza otite média crônica, mas a duração cumulativa é excessiva, tal como seis meses em um ano. Criança com deficiência auditiva de qualquer etiologia e que tem piora da audição devido à otite média secretora;

- episódios recorrentes de otite média aguda (OMA). A frequiência mínima para se indicar a colocação de TV é três ou mais episódios de OMA em seis meses, ou quatro ou mais episódios em um ano;

- presença ou suspeita de complicação supurativa. A colocação de TV no momento da miringotomia garante drenagem e aeração mais prolongada do ouvido médio e mastóide. Um exame bacterioscópico, cultura e antibiograma da secreção do ouvido médio devem ser realizados;

- disfunção da tuba auditiva, mesmo na ausência de secreção no ouvido médio, quando o paciente apresenta sinais e sintomas persistentes ou recorrentes, que não melhoram com tratamento clínico. Os sinais e sintomas incluem perda auditiva (geralmente flutuante), desequilíbrio/vertigem, zumbidos ou bolsa de retração timpânica severa.

Excluídas estas situações, pode-se tentar, inicialmente, um tratamento clínico da mesma forma relatada para a OMA, embora esta não seja uma conduta unânime.

Kay et al..$^{5}$ realizaram estudo de meta-análise de 134 artigos durante o período de 1966 até abril de 1999, para estimar a incidência das principais seqüelas ocorridas póscolocação do TV. As seqüelas encontradas durante a permanência do TV foram: obstrução do TV (7\% das orelhas), formação de tecido de granulação $(5 \%)$, queda prematura do TV $(3,9 \%)$ e deslocamento medial $(0,5 \%)$. As seqüelas ocorridas após a saída do TV incluem timpanosclerose (32\%), atrofia focal $(25 \%)$, bolsa de retração $(3,1 \%)$, colesteatoma $(0,7 \%)$ e perfuração $(2,2 \%$ para TV de curta duração e 16,6\% para os de longa duração). A meta-análise revelou que os TVs de longa duração aumentam o risco de perfuração em 3,5 vezes, e de colesteatoma em 2,6 vezes. A otorréia transitória ocorreu em $16 \%$ dos pacientes no período pós-operatório imediato, e $25 \%$, no tardio; a otorréia recorrente ocorreu em 7,4\%, e a otorréia crônica, em 3,8\%.
A otorréia ocorre em 21 a 50\% de todas as crianças com TV nos Estados Unidos da América. Nas crianças muito pequenas, os organismos tipicamente responsáveis pela otorréia são os mesmos da OMA, incluindo Streptococcus pneumoniae, Haemophilus influenzae e Moraxella catarrhalis. Nas crianças maiores, a otorréia costuma ser causada por organismos que colonizam a orelha externa, como Pseudomonas aeruginosa e Staphylococcus aureus ${ }^{2}$.

Desde a introdução dos TVs por Armstrong, em 1952, médicos e pacientes têm sido alertados sobre possíveis danos causados pela entrada de água dentro da orelha média, via tubo de ventilação. É comum que muitos médicos alertem as mães de seus pacientes para que evitem a entrada de água dentro da orelha média, usando protetores auriculares quando tiverem contato com água, principalmente a natação, hoje em dia tão em moda. Contudo, o possível efeito da água como causa de otorréia e/ou otalgia ainda é controverso.

Lee et al. ${ }^{6}$ realizaram estudo de meta-análise, reunindo trabalhos sobre crianças com TV e cuidados com natação e água. Estudando 619 crianças, não encontraram diferença significante na incidência de otorréia em pacientes que nadaram sem protetores auriculares e crianças que não nadaram após a colocação do TV. Como os estudos não foram randomizados, os autores sugerem que cada paciente deva ser orientado de forma individualizada.

Hebert et al. ${ }^{7}$ desenvolveram um modelo humano dotado de orelha externa, membrana timpânica com TV, mastóide e tuba auditiva com leitura da resistência com sensor (ohmmetro), para medir a passagem de água pelo TV, e efetuaram várias medições com diferentes tipos de água, concluindo que a água de chuveiro, a lavagem da cabeça e a submersão em água da torneira não favorecem a entrada de água na orelha média. Entretanto, a água com sabão aumenta a chance de passagem pelo TV. Em banhos de piscina, a incidência de passagem de água pelo TV aumentava com mergulhos a profundidades maiores que $60 \mathrm{~cm}$. Frente a estes resultados, concluem que existem fortes evidências demonstrando que muitas das precauções freqüentemente adotadas nos pacientes com TV são desnecessárias.

Tais trabalhos experimentais, como o de Hebert et al., citado acima, ou o de Saffer e Miura, publicado aqui nesta edição, são de grande valia para que se possa orientar corretamente sobre quais os cuidados que uma mãe deve adotar com uma criança operada para a colocação do TV, e os cuidados com a água durante todo o período em que o TV permanecer posicionado, o que pode significar 6 meses de duração, em média.

\section{Referências bibliográficas}

1. Kaplan B, Wandstrat TL. Pharmacoeconomic impact of factors affecting compliance with antibiotic regimens in the treatment of acute otitis media. Pediatr Infect Dis J 1997;16:S27-9. 
2. Goldblatt EL. Efficacy of ofloxacin and other otic preparations for acute otitis media in patients with tympanostomy tubes. Pediatr Infect Dis J 2001;20:116-9.

3. Saffer M, Silva DB, Peduzzi FD, Ávila F. Otite média crônica secretora: conduta expectante. J Pediatr (Rio J) 2000;76:407-12.

4. Pereira MBR, Ramos BD. Otite média aguda e secretora. J Pediatr (Rio J) 1998;74:S21-S30.
5. Kay DJ, Nelson M, Rosenfeld RM. Meta-analysis of tympanostomy tube sequelae. Otolaryngol Head Neck Surg 2001; 124:374-80.

6. Lee D, Youk A, Goldstein NA. A meta-analysis of swimming and water precautions. Laryngoscope 1999;109:536-40.

7. Hebert RL $2^{\text {nd }}$, King GE, Bent JP $3^{\text {rd }}$. Tympanostomy tubes and water exposure: a practical model. Arch Otolaryngol Head Neck Surg 1998; 124:1118-21. 